\title{
Nutritional training needs as perceived by preschool managers of full-day-care preschools in Dublin North West
}

\author{
A. Jennings ${ }^{1}$, S. McEvoy ${ }^{2}$ and C. Corish ${ }^{1}$ \\ ${ }^{1}$ School of Biological Sciences, Dublin Institute of Technology, Kevin Street, Dublin 8, Republic of Ireland and ${ }^{2}$ Health \\ Promotion Unit, Health Service Executive Dublin North East, Dublin 7, Republic of Ireland
}

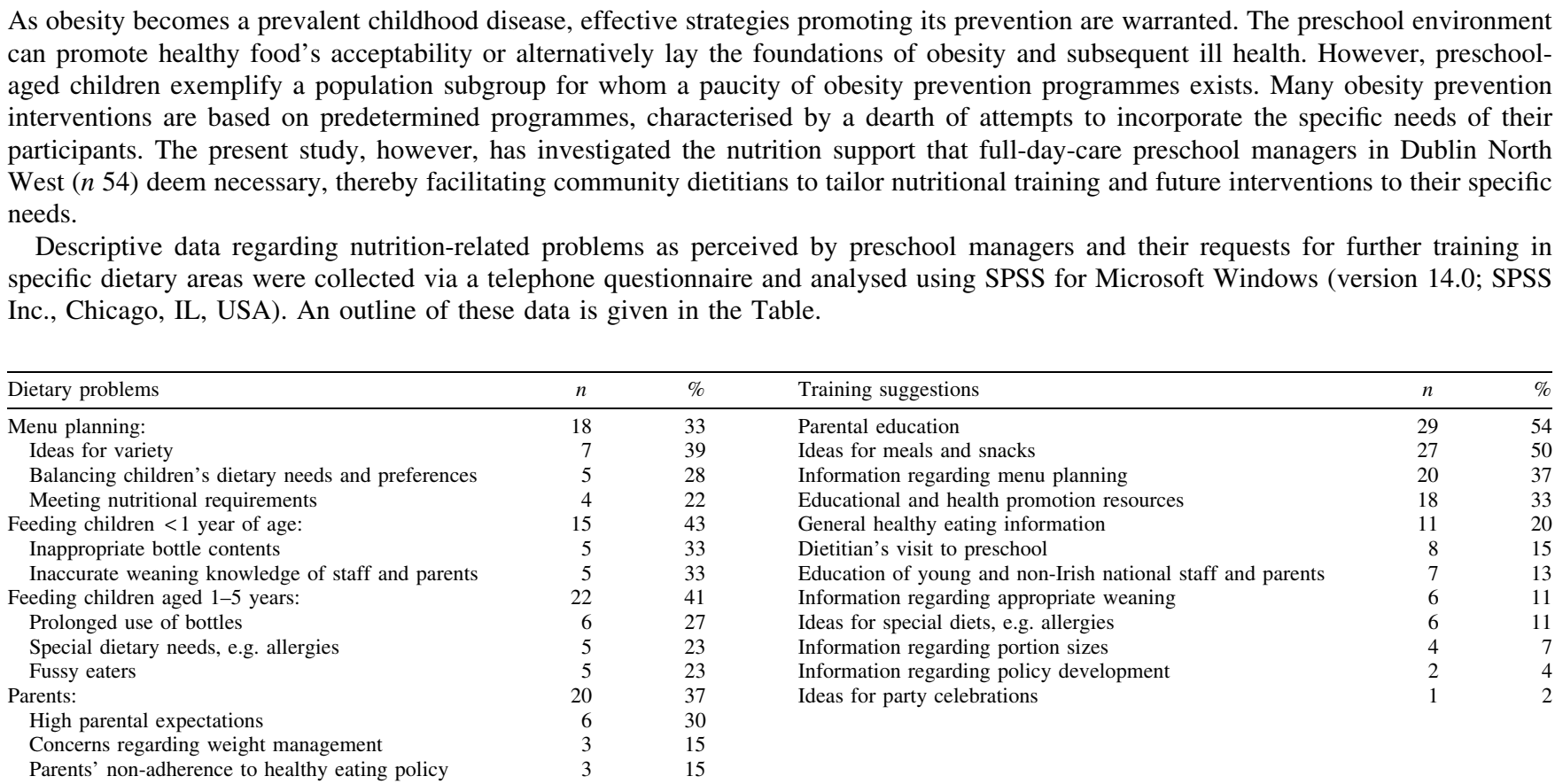

Concerns were expressed by twenty-three managers that children would refuse to eat food from a healthy menu. Eight managers reported difficulty in the provision of a healthy diet within the preschool setting, citing poor home diets, parental attitudes and lack of staff interest as contributing factors. All except one of the preschools ( $n$ 53) identified the need for further nutritional training. Provision of training on the preschool premises $(n 25)$ outside normal working hours $(n 48)$ was most favourable to managers.

In this study, long preschool working hours and staff perceptions of their responsibility in the endorsement of healthy eating is likely to influence training attendance. However, continued training is warranted, as recognised by preschool managers who specify the need for parental education, ideas for food provision and menu planning, in addition to the provision of appropriate nutritional resources as training priorities. Additionally, training should aim to increase awareness of the important role preschools play in the acquisition of dietary habits in the preschool child, while highlighting the supportive role of the community dietitian. 